\title{
On the possibilities of situational and semantic analysis in the study of professional thinking of higher school teachers to ensure constructive pedagogical communication
}

\author{
O.N. Rakitskaya ${ }^{1 *}$, D.A. Kuznetsova ${ }^{2}$, and Yu.V. Smirnova ${ }^{3}$ \\ ${ }^{1}$ Federal state educational institution of higher professional education «Vologda Institute of law and \\ Economics of the Federal penal service», Vologda, Russia \\ ${ }^{2}$ Federal state educational institution of higher professional education «Vologda Institute of law and \\ Economics of the Federal penal service», Vologda, Russia \\ ${ }^{3}$ Federal state educational institution of higher professional education «Vologda Institute of law and \\ Economics of the Federal penal service», Vologda, Russia
}

\begin{abstract}
The article presents some results of a complex research of the social and psychological characteristics of teachers' professional thinking which provides interaction between the teacher and the learner in higher school classes. The understanding of the pedagogical situation as a problematic issue in the comparative analysis of militarized and civil university teachers is studied. It is proved that it is necessary to analyze pedagogical situations and find out the subjective meanings that determine the understanding of their problematic character in the psychological and pedagogical support of higher school teachers' professional training.
\end{abstract}

\section{A problem statement}

Many researchers assert that the effectiveness of teaching, including higher education, depends not only on the degree of erudition and the teachers' knowledge of the subject, but also on their communicative competence. The system of relations between teachers and students can both promote productive interaction and hinder it in case of conflict experience accumulation. The core of conflicts is the original contradiction or problem. Positive results in conflicts will largely depend on solving the problem. From our point of view, the solution of problem situations that arise in pedagogical communication between the subjects of the educational process depends mainly on the personality of the teacher and the peculiarities of his professional thinking. Consequently, the teacher's thinking ensures his competence in solving problems that arise in pedagogical communication.

The teacher's thinking belongs to a type of practical thinking, which, according to Yu.K. Kornilov, is closely connected with real activity. Besides it does not only affect its implementation, but also is formed in it. In the course of practical thinking functioning,

*Corresponding author: ipcs-profped@yandex.ru 
generalizations of empirical data appear, which form this or that knowledge, these or other meanings. Moreover, this knowledge is usually poorly realized and non-verbalized, although it differs in its readiness to be implemented in external actions [1].

E.N. Korneeva, while studying communication between students and teachers as a particular type of social interaction in teaching, believes that it is affected by integrative regulators (personal-subjective, subject-situational, subject-interactive). In this case, the individual characteristics of the subjects' interaction are transformed by social influences and counteractions, expectations and forecasts that influence its result. E.N. Korneeva believes that the participants of interaction make their own contribution to it, while bearing different responsibilities [2].

We can say that practical activity helps teachers form their subjective system of meanings that allows them navigate in current situations and identify them as problematic or not problematic. The detection of subjective problems in a stimulus situation can lead to the formulation of a problem that requires a solution, which, in turn, will be based on the existing experience presented in the system of teacher's subjective meanings.

Thus, there is a need to study the teachers' subjective meanings as units of practical thinking that provide an understanding of current communicative situations and determine actions, including the resolution of problems found in them.

\subsection{The objective of the work}

According to researchers of the Yaroslavl school of psychology (E.V. Drapak, E.V. Koneva, Yu.K. Kornilov, N.N. Mekhtikhanova, A.V. Pankratov, V.K. Solondaev, S.A. Trifonova, etc.), the initial stage of thinking in practice is a problem situation preceded by a stimulus situation that reflects a set of environmental conditions. The transformation of a stimulus situation into a problem one does not happen by itself but is determined by the work of practical thinking.

D.N. Zavalishina draws attention to the fact that for thinking that is formed in the conditions of practical activity, any parameter of the stimulus situation can be distinguished from other conditions as essential, as well as contradicting some of these conditions. Moreover, the same stimulus situation can cause different specialists different understanding of problem situations [3].

That is why the researchers mentioned above consider the personal meaning as a primary link between the peculiarities of the subject's personality and the process of practical thinking. It is the personal meaning which reflects the problem in the stimulus situation and determines mental - in our case, pedagogical, - task which unites the subject features of a person $[4,5,6,7,8]$.

While studying pedagogical thinking, M.M. Kashapov points out that personal meaning in the course of perception of the current educational activity conditions makes it possible to identify problems in the pedagogical situation. At the same time, the essence of the problem is not in the fact of a deficit or contradiction implied in information, but in the fact that the teacher subjectively recognizes them [9].

According to M.M. Kashapov, a creative solution in the work of a professional is possible only if he has a subjective problem in a pedagogical situation that allows him to set a pedagogical task. Such a problem stimulates a person in the search of a new solution, solving a problematic pedagogical situation [10].

V.A. Popkov and A.V. Korzhuev state that critical thinking is a necessary condition in discussing the requirements for the teacher's personality in the higher education system. They realize that the criticality is determined by the capacity for reflection and define critical thinking as "a specific form of assessment activities of a subject of cognition, aimed at (in its most general sense) identifying the degree of compliance (or noncompliance) of a 
product to benchmarks and standards, including specific procedures and contributing to the semantic determination of the subject of cognition in relation to various manifestations of the world and its productive transformation" [11, p. 221]. Besides the teacher's reflexivity, they expect his thinking to be tolerant, ensuring productive teaching activity. Tolerance, together with contradictions and shortcomings, provides the teacher with such solutions that will help to establish and achieve agreement in relations with learners [11].

We believe the communicative nature of pedagogical activity determines the formation of professional thinking in its subjects, which is focused on the interaction partner in the educational process. Pedagogical thinking should ensure the ability of teachers to understand the structure and content of both their own mental activity and the student's thinking, taking into account the revealed opportunities and limitations, the presentation of their own reasoning to the partner in an accessible form. In this regard, we have studied such characteristics of professional pedagogical thinking as dialogicality, reflexivity and criticality that reflect its social and psychological functions $[12,13]$.

So, the practical thinking of higher school teachers is aimed at ensuring effective social interaction in the framework of education, where a number of typical situations can be pointed out, including problematic ones. According to E.N. Korneeva, each of these situations needs its own type of teacher's professional competence [14].

T.G. Kiseleva identifies professional thinking the core of pedagogical competence and presents it as a process of search, detection and resolution of problematic pedagogical situation [15]. Since the teacher's professional thinking is most clearly revealed in the reconstruction of a problem situation, it is necessary to identify situations of this kind and use them at different stages of psychological and pedagogical training of teachers.

Clarification of typical problematic pedagogical situations should be accompanied by the study of the content aspects of thinking, represented in the meanings that the teacher operates with. According to L.S. Vygotsky, individual meaning is both a means and a product of cognition, while it contains all the signs of thinking process, and represents a necessary unit in analysis of thinking, including practical [16].

Thus, an applied research of the teachers' subjective meanings that determine the perception of potentially problematic pedagogical situations, will help to reveal the mechanism for detecting problems and foresee possible actions of teachers in problematic pedagogical situations. At the same time, semantic analysis should be preceded by the identification of typical problematic pedagogical situations that actualize the systems of teachers' semantic meanings.

\section{Materials and the results of the research}

The participants of the research were teachers of higher educational institutions of the Ministry of education and science of the Russian Federation and the Federal penitentiary service of Russia. The comparative nature of the study was organized due to the fact that the practical thinking of teachers who combine their activities with the penal service is introduced in specific social and psychological conditions.

To determine the conditions of teacher's professional thinking, we studied the problem situations typical for pedagogical practice in higher education. Having analyzed one hundred examples of problem situations received in the course of a preliminary survey of teachers $(n=30)$, twelve typical stimulus situations were constructed and offered to the subjects $(\mathrm{n}=118)$ for ranking by the degree of subjective significance and relevance. As a result, the following four groups of problem situations were pointed out: very significant, significant, insignificant and not significant.

The experimental study of subjective meanings revealed in problematic situations in the activities of both departmental and civil higher education institutions teachers was held 
using the computerized method of repertoire grids "Kelly-98" (V.M. Vorobyov, N.L. Konovalova) [17]. The results of the study were clarified in an interview with the participants. At this stage, the sample included 40 teachers of departmental $(n=20)$ and civil higher education institutions $(n=20)$, whose system of individual meanings was studied by content analysis. Then the semantic spaces of the teachers of these groups were obtained. The semantic spaces reflected the understanding of what was happening and determined the potential behavior in the current communication. The characteristic of the teachers' problem under research was done on the basis of comparative analysis using quantitative methods (calculation of the percentage ratio, nonparametric Mann-Whitney criterion in the statistical computer program SPSS 12.0) and qualitative analysis.

It should be noted that the stimulus situations offered for ranking reflect the difficulties of teachers in the following conditions: when learners violate the prescribed rules of behaviour (violations of discipline), when transmitting material to an unmotivated learner who has a low level of training (learning problems), when organizing their activities under assessing the level of their professional competence. The set of problems is presented in tables 1-4.

Table 1. The most relevant problem situations for teachers' activity at the University.

\begin{tabular}{|l|l|l|}
\hline \multirow{2}{*}{ Rating } & $\begin{array}{l}\text { Brief description of civil teachers } \\
\text { problematic pedagogical situation }\end{array}$ & $\begin{array}{l}\text { Brief description of departmental } \\
\text { teachers problematic pedagogical } \\
\text { situation }\end{array}$ \\
\hline 1 & $\begin{array}{l}\text { The teacher is to evaluate students who } \\
\text { are diligent, but "average" in ability, and } \\
\text { students who are less diligent, but more } \\
\text { intellectual, according to the same criteria. }\end{array}$ & $\begin{array}{l}\text { The teacher has to complete a number of } \\
\text { tasks in a short time. }\end{array}$ \\
\hline 2 & $\begin{array}{l}\text { The teacher is to conduct a seminar in } \\
\text { the group that is not prepared for the } \\
\text { lesson. }\end{array}$ \\
\hline 3 & $\begin{array}{l}\text { The teacher is to conduct a seminar in the } \\
\text { group that is not prepared for the lesson. }\end{array}$ & $\begin{array}{l}\text { The teacher is to evaluate according to } \\
\text { the same criteria diligent but "average" } \\
\text { military students and those who are less } \\
\text { diligent, but more intellectual. }\end{array}$ \\
\hline & $\begin{array}{l}\text { The teacher has to explain the lecture } \\
\text { several times, because there are some } \\
\text { students who do not understand what is } \\
\text { being said. }\end{array}$ & $\begin{array}{l}\text { The teacher has to explain several times } \\
\text { the lecture, because some military } \\
\text { students do not understand what is being } \\
\text { said. }\end{array}$ \\
\cline { 3 - 3 } & $\begin{array}{l}\text { The teacher does not know the answer to } \\
\text { the student's question. }\end{array}$ \\
\hline
\end{tabular}

Table 1 shows that some of the most urgent problem situations for teachers of civil and departmental universities coincide, while the number of actual problems of departmental teachers is higher, and they have specific difficulties in communicating with learners.

Both groups of teachers consider interaction with learners who show different degrees of mastering the material and different degrees of motivation to be the actual problem. It is difficult to assess the amount of efforts made by less capable students and the poor preparation of those who compensate for this with intellectual capabilities. At the same time, the assessment of "weak" but diligent learners increases and performs a stimulating function, but causes certain worries of the teacher who evaluates. These worries are associated with deviation from the unified assessment system.

The special part of the problems noted by teachers in both groups is related to the low level of general erudition, training in disciplines studied earlier and poor preparation for classes that stumble the educational process. In this case the teacher has to deviate from the lesson plan, switch attention to questions that are not directly related to the topic, but are the basis for its understanding. The subjective feeling of complexity is worsened by the fact 
that the most prepared learners have to go over the information known before and they may show dissatisfaction and lose motivation to further development.

The situation of urgent completion of a great number of tasks within a short period of time takes the first place with departmental teachers, while for civil university teachers it is referred to insignificant problem situations. The interview revealed that teachers of civil universities are more independent in the distribution of priorities and the designation of deadlines for work. They can cancel certain tasks (such as attending a conference) if they can't handle the amount of work they are doing currently. In departmental higher education institutions, we face strict control over the implementation of planned activities that are monitored in accordance with the schedule. The violation of rules may lead to administrative or financial penalties for the teacher. Such an "emergency" when the deadlines for performing different works coincide causes tension due to the need for their urgent implementation, as well as teachers' negative emotions caused by doubts about the quality of the results of their work. The power of the tension depends on the teacher's demands for these results.

In addition, the situations when teachers of departmental universities cannot give an answer to a learner's question are considered to be significant. This may be due to the subordination relationship that puts teachers in a higher position in relation with the learners and does not admit the possibility to change this position. Teachers' incompetence in some cases extends to the assessment of the possibility of occupying a higher position. Naturally, such difficulties cause the teacher experience additional stress, the need to increase the amount of memorized information and the inability always do it because of the "emergency" of the activity mentioned above. Civilian teachers are more likely to accept their own limited knowledge, which is emphasized by the inability to "know everything". They can assess the possibility of obtaining new information in a positive way, therefore the situations of evaluating their own professional competence are less problematic for them.

Situations of medium, low significance and irrelevant for both groups of teachers are presented in tables 2-4.

Table 2. Problem situations of medium significance for teachers.

\begin{tabular}{|l|l|l|}
\hline Rating & $\begin{array}{l}\text { Brief description of civil teachers ' } \\
\text { problematic pedagogical situation }\end{array}$ & $\begin{array}{l}\text { Brief description of departmental } \\
\text { teachers problematic pedagogical } \\
\text { situation }\end{array}$ \\
\hline 4 & $\begin{array}{l}\text { The teacher is to evaluate students who are } \\
\text { diligent, but "average" in ability, and } \\
\text { students who are less diligent, but more } \\
\text { intellectual, according to the same criteria. }\end{array}$ & $\begin{array}{l}\text { The teacher's offer to perform a creative } \\
\text { task is not accepted by any learner in the } \\
\text { group. }\end{array}$ \\
\cline { 2 - 4 } & $\begin{array}{l}\text { The teacher's enthusiastic speech at the } \\
\text { lecture is interrupted by the students } \\
\text { demand to dictate, repeat word by word } \\
\text { what was said. }\end{array}$ & $\begin{array}{l}\text { The teacher's enthusiastic speech at the } \\
\text { lecture is interrupted by the students ' } \\
\text { demand to dictate, repeat word by word } \\
\text { what was said. }\end{array}$ \\
\hline 6 & $\begin{array}{l}\text { The teacher does not know the answer to the } \\
\text { student's question. }\end{array}$ & $\begin{array}{l}\text { The learners who sit at the last desks are } \\
\text { doing with their "business". }\end{array}$ \\
\hline
\end{tabular}

Table 3. Problem situations that are insignificant for teachers.

\begin{tabular}{|l|l|l|}
\hline Rating & $\begin{array}{l}\text { Brief description of civil teachers ' } \\
\text { problematic pedagogical situation }\end{array}$ & $\begin{array}{l}\text { Brief description of departmental } \\
\text { teachers problematic } \\
\text { situation }\end{array}$ \\
\hline 7 & $\begin{array}{l}\text { The teacher is to complete a number of } \\
\text { tasks in a short period of time. }\end{array}$ & $\begin{array}{l}\text { Learners express distrust and doubt in } \\
\text { teacher's professional competence. }\end{array}$ \\
\cline { 3 - 4 } & & $\begin{array}{l}\text { The teacher's enthusiastic speech at the } \\
\text { lecture is interrupted by the students }\end{array}$ \\
\hline
\end{tabular}




\begin{tabular}{|l|l|l|}
\hline Rating & $\begin{array}{l}\text { Brief description of civil teachers ' } \\
\text { problematic pedagogical situation }\end{array}$ & $\begin{array}{l}\text { Brief description of departmental } \\
\text { teachers problematic } \\
\text { situation }\end{array}$ \\
\hline & $\begin{array}{l}\text { pedagogical } \\
\text { what was said. }\end{array}$ \\
\hline 8 & $\begin{array}{l}\text { The teacher's offer to do a creative task is } \\
\text { not accepted by any student in the group. }\end{array}$ & - \\
\hline 9 & $\begin{array}{l}\text { The student accuses the teacher of being } \\
\text { prejudiced during the assessment. }\end{array}$ & $\begin{array}{l}\text { The learner begs for a grade, asks to raise } \\
\text { it. }\end{array}$ \\
\hline
\end{tabular}

Table 4. Problem situations that are not relevant for University teachers.

\begin{tabular}{|l|l|l|}
\hline Rating & $\begin{array}{l}\text { Brief description of civil teachers } \\
\text { problematic pedagogical situation }\end{array}$ & $\begin{array}{l}\text { Brief description of departmental } \\
\text { teachers problematic } \\
\text { situation }\end{array}$ \\
\hline 10 & $\begin{array}{l}\text { The teacher does not know the answer to } \\
\text { the student's question. }\end{array}$ & - \\
\hline 11 & $\begin{array}{l}\text { The learners who sit at the last desks are } \\
\text { doing with their "business". }\end{array}$ & $\begin{array}{l}\text { In response to the teacher's remark, the } \\
\text { learner irritably does not admit his guilt in } \\
\text { breaking the discipline. }\end{array}$ \\
\cline { 2 - 3 } & $\begin{array}{l}\text { The student begs for a grade, asks to raise } \\
\text { it. }\end{array}$ & $\begin{array}{l}\text { Learners express distrust and doubt in } \\
\text { teacher's professional competence. }\end{array}$ \\
\hline 12 & $\begin{array}{l}\text { Students express distrust and doubt in } \\
\text { teacher's professional competence. }\end{array}$ & $\begin{array}{l}\text { The student accuses the teacher of being } \\
\text { prejudiced during the assessment. The } \\
\text { student accuses the teacher of bias during } \\
\text { the assessment. }\end{array}$ \\
$\begin{array}{l}\text { In response to the teacher's remark the } \\
\text { student irritably does not admit his guilt in } \\
\text { violation of discipline. }\end{array}$ & \multicolumn{2}{|l}{} \\
\hline
\end{tabular}

Both groups of teachers refer to situations of moderate significance the inability of students to fix the lecture without repetition and dictation. Such restrictions lead to simplification of the presentation, the need to focus only on memorized phrases in order to repeat them verbatim, and a decrease in the amount of material that is voiced at the lecture. In addition, for departmental teachers the lack of learners' interest in performing creative tasks is a significant problem as well as those who are engaged in extraneous matters in the classroom. This may be of less relevance for civilian teachers, since their students do not combine their academic activities with their official ones, and are more motivated for different forms of education, and have more spare time. Besides, the registration of attendance at civil universities is less strict, so those who plan to do their own business may simply not come to classes.

The group of least relevant situations for civil teachers includes a large number of situations. Insignificant are situations in which there is a violation of the rules of conduct in professional interaction related to professional competence. To the assumptions described above, let us add that the general cultural level of students who have passed the competitive selection to the University determines the knowledge of the rules of communication and the rarity of situations with inappropriate behavior in the classroom. Teachers can ignore "disciplinary" situations, inappropriate behavior because they do not associate them with their behavior, consider them to be of no significance. Such ignoring may be associated with the desire to push out such worries and isolate themselves from interacting with an "inconvenient" partner, "to be above it".

Departmental teachers consider situations with rude learners' responses to be irrelevant, since the established forms of relationships in a departmental institution exclude such behavior of a learner; it is equated to a disciplinary violation of subordination. The same reason leads to the rarity of situations where a departmental teacher is charged with professional incompetence, which is articulated when formulating questions (described above), but cannot be expressed directly due to the norms of the institution. Perhaps it is the 
lack of ways to express directly complaints that provokes a more scrupulous attitude of teachers to the inability to answer the question, since they have a subjective feeling of showing the learner's position in this way.

In both groups learner's "rudeness" in the classroom is mostly an insignificant situation as well as the situation of accusations or doubts about the teacher's professional competence on the part of the learner because such situations are rather rare. Teachers tend not to take these situations "seriously", as they are more competent in the issue. Both of these situations are characterized by a pronounced negative, conflicting background of relations in which the teacher objectively has great advantages in case of competition. Besides the teacher most likely does not value the relationship with such a partner. The arrangement of these situations may be due to their irrelevance.

At the next stage of the research the study of individual semantic spaces through which the subjects detect problems in the stimulus problematic pedagogical situations, was carried out. It was done by using a modified J. Kelly's test of repertoire grids (computer version of "Kelly - 98") [17]. The method allows us to identify 12 pairs of subjectively dichotomous characteristics (constructs) for each subject based on the presentation of stimulus material (12 problem situations) by the "triad" method.

As a result, 480 constructs were obtained. They were divided into three groups in accordance with the universal factors ("score", "activity", "strength") proposed by Ch. Osgood [18], in each of which we identified additional categories. The description of universal factors that organize the teachers' consciousness in the perception of problematic pedagogical situations is presented in table 5 .

Table 5. Factors of semantic space of higher school teachers.

\begin{tabular}{|c|c|c|}
\hline Factor & Category & The meanings of the selected categories \\
\hline \multirow[t]{4}{*}{ Score } & evaluating your position & $\begin{array}{l}\text { "possible incompetence", "I am active - I am } \\
\text { passive", "requires skills, abilities", "is associated } \\
\text { with a set of knowledge", "uncertainty» }\end{array}$ \\
\hline & partner assessment & "doesn't want", "can't", "provokes conflict» \\
\hline & emotion assessment & $\begin{array}{l}\text { reflects the degree of expression of teacher's } \\
\text { emotional reactions to the situation from "neutral" } \\
\text { ("no difference", "no reaction", "normal") to } \\
\text { extreme manifestations of emotions ("surprising", } \\
\text { "upsetting", "infuriating", etc.) }\end{array}$ \\
\hline & relation assessment & $\begin{array}{l}\text { reflects the nature of interaction between } \\
\text { participants in the situation from maintaining } \\
\text { emotional involvement and a certain degree of } \\
\text { trust ("acceptance of the situation", "related to } \\
\text { understanding", etc.) to formalizing relationships } \\
\text { characterized by emotional closeness, "coldness", } \\
\text { distrust ("no mutual understanding", "lack of } \\
\text { enthusiasm", etc. }\end{array}$ \\
\hline \multirow[t]{2}{*}{ Activity } & direction of activity & $\begin{array}{l}\text { - towards the partner while maintaining interaction } \\
\text { ("I focus on the other", "empathic involvement", } \\
\text { "activity", "contact", etc.) } \\
\text { - withdrawal from the partner and termination of } \\
\text { interaction ("hands down", "passivity", "distance } \\
\text { in the relationship", etc.) }\end{array}$ \\
\hline & content of activity & $\begin{array}{l}\text { - the desire to understand the partner and the } \\
\text { situation ("understanding", "adjusting to the } \\
\text { situation") } \\
\text { - actions to suppress or prevent undesirable } \\
\text { partner's behavior ("desire to stop interaction", }\end{array}$ \\
\hline
\end{tabular}




\begin{tabular}{|c|c|c|}
\hline Factor & Category & The meanings of the selected categories \\
\hline & & $\begin{array}{l}\text { "bewilderment", "feeling of superiority", "self- } \\
\text { guided", etc.) }\end{array}$ \\
\hline & boundaries of activity & $\begin{array}{l}\text { - a choice of activities ("creativity", "can be } \\
\text { varied", "there are other solutions") } \\
\text { - lack of choice, which implies the certainty of } \\
\text { actions and activity forms ("routine", "the choice } \\
\text { of solution is determined", "the only solution", } \\
\text { etc.) }\end{array}$ \\
\hline \multirow[t]{2}{*}{ Strength } & $\begin{array}{l}\text { tension of experiencing a } \\
\text { problem }\end{array}$ & $\begin{array}{l}\text { - uncertainty of the decision when there is a } \\
\text { subjective need to resolve the situation ("it is more } \\
\text { difficult to solve", "I will try", "we need to do } \\
\text { something", "mobilization of forces", etc.) } \\
\text { - availability of a specific ready-made solution } \\
\text { with a less pronounced willingness to act ("quick } \\
\text { resolution", "easier to solve", "don't care", "do } \\
\text { nothing») }\end{array}$ \\
\hline & $\begin{array}{l}\text { responsibility for solving } \\
\text { the problem }\end{array}$ & $\begin{array}{l}\text { - distribution of responsibility for the decision } \\
\text { between partners ("depends - does not depend on } \\
\text { the teacher", "I control everything", "requires the } \\
\text { partner's efforts", "not my problems", etc.) } \\
\text { - the possibility to change the situation ("there are } \\
\text { possible solutions", "accept as inevitable", } \\
\text { "possibility of exit", etc.) }\end{array}$ \\
\hline
\end{tabular}

The comparative analysis (the Mann-Whitney U-test) showed no significant differences in the distribution of the obtained individual meanings (constructs) both for departmental and civil teachers that confirmed the universal nature of the factors and their characteristics.

It should be noted that the largest number of meanings relate to the assessment factor, both for departmental (45.8\%) and civil (43.8\%) teachers. This is probably due to the need to evaluate in problematic pedagogical situations several components (the four components for assessment presented above).

The similarity of data in the presented experimental groups may indicate that in the course of understanding pedagogical problem situations, teachers tend to evaluate the participants, the relationship between them. It reflects the criticality of practical thinking of teachers. The results of this assessment - the ratio of the identified advantages and disadvantages - determine the quality and nature of the teacher's emotional response to the situation. The largest number of meanings in the "assessment" category (36\%) are referred to the emotional assessment of the situation, since the contradiction of the situation has different degrees of conflict from "tolerable", "normal" to "clearly annoying". About one third of the meanings in the "rating" category relate to the partners' perception in the situation, understanding their personality and behavior, and explaining their actions to themselves. At the same time, the least number of meanings in this category refers to the assessment of the teacher's own position in the situation (15\%), which indicates a greater criticism of the partner than of themselves.

The meanings in the "activity" category reflect the nature of actions, most of which are oriented at the learner (66-72\%). Almost the same number of participants' meanings reflects the nature of interaction with learners $(20 \%)$, associated with the establishment of mutual understanding or the suppression of partner's unwanted activity. Personality constructs that describe the choices of action solutions to the situation or the limits of behavior ("uniformity of methods", "variety of approaches") civil teachers demonstrate more often $(14 \%)$ than departmental $(8 \%)$ teachers.

Concerning the category of "strength" that reflects the teacher's tension of mental activity in problematic pedagogical situations, it is possible to speak about presence of 
subjective experiences of problems and the need for their resolution (70\%) in both groups ("we need to intervene", "requires effort", "something to do", etc.). About one third of the meanings reflects the desire of teachers to decide on a possible solution or to abandon it, acknowledging the impossibility of changing the situation ("accept as inevitable", "the choice among my priorities", "not up to me", "the consequences for the partner," etc.). That is, if there is a noticeable tension, it is possible to talk about making a decision in the problematic pedagogical situations only for a third of the participants.

Thus, in accordance with the universal factors of semantic spaces, the mechanism of perception of problematic pedagogical situations is outlined. It turned out that in problem situations the students' actions that are recognized as non-compliant with the teacher's requirements and accompanied by negative experiences are mainly assessed. When experiencing subjective problems and the associated psychoemotional stress that determines the readiness for action, the actions themselves to resolve the situation are not often presented. In other words, the teachers experiencing the problematic pedagogical situation will react with directive actions aimed at students. Unfortunately, the focus on finding and choosing solutions to the problematic pedagogical situation with the acceptance of their own responsibility for changing the situation is poorly demonstrated.

At the next stage of the study we used the "Kelly - 98" method to identify systems of subjective meanings, typical for our participants, based on the calculation of intercorrelations between estimates of stimulus situations on the scales of personal constructs. The program allows us to get factors that connect individual meanings and construct a semantic space for each participant. As a result, we refined the subjects' ideas about the required problematic pedagogical situation based on the description and analysis of the most significant first three factors in each experimental group.

The emotional nature of the response that we found at the previous stages of the study was confirmed while analyzing the combination of the first factors of civil teachers. We called it the "emotional subjective problem" factor because it defines the understanding of a situation as "emotionally affecting" or "indifferent". Moreover, in comparison with the other two factors, which are fragmentary in content, the first one turned out to be relatively homogeneous. It turned out that if teachers do not detect signs of hostility towards the student ("there is no negative reaction from the partner", they do not "attack", but "ask"), then they are ready to continue interacting with learners, even if they are not diligent enough, but motivated to learning ("there is an interest in knowledge"). The analysis of the first factor in combination with the "analytical-orientation" and the "choice of solution" factor allows us to understand that the problem that encourages teachers to search for creative solutions, is the training of an interested but insufficiently capable learner. Subjectsubject interaction is suppressed and relationships are formalized in case the learner is assessed as unmotivated to learning.

The meanings of the first factors in the group of departmental teachers reflect the emotional experience of problematic pedagogical situation to a lesser extent in comparison with civil colleagues. This factor reflects the assessment of the partner's intentions as focused on interaction or refusing it to a greater extent. The result of the partner's assessment is the decision to either cooperate or compete with them, which allowed us to call this factor "choice of the type of interaction". In combination with the second ("definition of the responsible person") and third ("experience of subjective problems") factors, an idea of the teachers' understanding the peculiarities of problematic pedagogical situation is formed. The experience of the problematic pedagogical situation's problems appears in case of relatively equal interaction with a partner who is ready to cooperate in the education. Moreover, a problem situation is more emotionally experienced if a person takes his own responsibility for it. 


\section{Conclusions}

While analyzing the problematic pedagogical experience we see common communicative difficulties typical for the teachers' professional activity. The teachers unanimously see the problem in the need of interacting with learners who do not meet their expectations and requirements. Due to insufficient motivation and/or abilities of the learners, the teachers need to find new ways of teaching and develop an assessment system.

Situational analysis helped us to reveal the specific features of the departmental teachers' problems associated, on the one hand, with multitasking of their professional activities that lead to situations of "emergency", and the urgent need to preserve self-esteem and authority before students.

Psychosemantic analysis helped us to reconstruct the systems of meanings expressed in verbal form that determine the teachers' perception of problems in pedagogical situations. On the basis of the data obtained it is possible to foresee the civil and departmental teachers' behavior in problematic pedagogical situations.

We found out that the teachers' pedagogical problems are associated with the training of a weak learner, who is perceived as a person interested in studies and interaction with teachers. In this case, pedagogical communication will be organized in a dialogue based on the collaboration. We can also predict high teacher's activity who is trying to solve the problem and explain the material in accordance with the learner's abilities, and perhaps develop his abilities to a demanded level.

It should be mentioned that teachers ' assessment of a learner as an insufficiently motivated person can lead either to the rejection of subject-subject relations and teacher's formalized interaction (as it was expressed by civil teachers), or to the choice of directive measures of influence (as it was expressed by departmental teachers).

It is obvious that the teachers do not treat the lack of learners' educational and cognitive motivation as a separate problem that needs to be solved. Moreover, attributing responsibility for the problematic pedagogical situations to an unmotivated partner is associated with a decrease of departmental teachers' subjective problem. In other words, not only the learner with unformed motivation is devalued, but also the problematic pedagogical situations itself, which is excluded from the teacher's consciousness as the situation that requires a solution. Unfortunately, our participants are not interested in the reasons why the learners have no interest in the subject they study. If they had an idea of the numerous reasons for this, it would reduce the teachers' straightforwardness when they assess the learners.

The following conclusion that draws teachers' and psychologists' attention is the orientation of teachers' assessment in the perception of problematic pedagogical situations mainly on learners. The shift in the focus of criticism of teachers participating in the experiment from their own activities to the behavior of a learner as a partner in the problematic pedagogical situations may reflect both insufficient reflexivity and pronounced psychological vulnerability. The signs of negative emotional experiences are especially noticeable among departmental teachers in problematic pedagogical situations, the solution of which is related to their competence and responsibility. Therefore we can predict the teachers' desire to avoid self-assessment in order to prevent subjectively unbearable experiences. These data demonstrate that higher school teachers may need not only additional professional training, but psychological support as well.

Psychoemotional stress that accompanies and marks the process of identifying subjective problems in pedagogical situations ensures the "inclusion" of the teacher in these situations, on the one hand. On the other hand, being excessive, this tension not only prevents from finding a solution to the problem but also stimulates psychological protection from unpleasant experiences that lead to non-constructive forms of pedagogical 
communication. Perhaps a number of teachers may be tempted to choose a less burdensome option while choosing between the active position of the partnership associated with responsibility and finding a solution to the original contradiction, and the redistribution of responsibility to the partner accompanied by a reduction in subjective problems.

Thus, the use of situational and semantic analysis of problematic pedagogical situations in teaching and the pedagogical activity of higher school teachers allows not only to reveal the features of the functioning of professional thinking, but also to promote its development. The development of the content and the flexibility of system of subjective meanings ensures the optimization of both teachers' relations towards themselves and the learner.

\section{References}

1. Yu.K. Kornilov, Psychology of practical thinking, p. 205 (Monograph, Yaroslavl, 2000)

2. E.N. Korneeva, Using the concept of integrative regulation of social interaction in assessing the competence of a higher school teacher and in order to improve it, Higher school at the present stage: psychology of teaching and learning: international collection of articles, 2, 77-79 (Ed. by prof. M. M. Kashapov, Moscow: Yaroslavl, Russian psychological society, 2005)

3. D.N. Zavalishina, Practical thinking: Specific features and problems of development, p. 376 (Moscow, The publ. house "Institute of psychology of the Russian Academy of Sciences", 2005)

4. E.V. Koneva, Features of individual classification of experience in professional thinking, Practical thinking: specifics of generalization, nature of verbalization and realization of knowledge: collection of articles, p. 143. (Ed. by Yu.K. Kornilov. Yaroslavl: The Publ. house Yaroslavl state University, 1997)

5. Yu.K. Kornilov, What task does a professional solve? Reflexive approach to psychological support of education: collection of articles, p. 222-228 (Ed. by A.V. Karpov, I.N. Semenova. Moscow. Yaroslavl: Remder, 2004)

6. Thinking and communication: active interaction with the world (Ed. by Yu.K. Kornilov, Yaroslav1, 1986)

7. Thinking and the subjective world, p. 104 (Ed. by Yu.K. Kornilov, Yaroslavl 1991)

8. N.N. Mekhtikhanov, A study of practical reasoning: methodological problems. Practical thinking and experience: pragmatism and instrumentality generalizations: collection of articles, 115-136 (Ed. by J.K. Kornilov, Yaroslavl: The Publ. house YarSU, 2000)

9. M.M. Kashapov, Psychology of professional pedagogical thinking (methodology, theory, practice), p. 73-144 (Monograph, Ed. by M.M. Kashapov, Moscow: Institute of psychology of the Russian Academy of Sciences, 2003)

10. M.M. Kashapov, Improving the creative thinking of a professional, p. 316 (Monograph, Ed. by prof. A.V. Karpov, Moscow; Yaroslavl: MAPN, 2006)

11. V.A. Popkov, Theory and practice of higher professional education: a manual, p. 432 (Moscow: Academic Project, 2004)

12. O.N. Rakitskaya, Dialogicality and criticality as socio-psychological characteristics of professional pedagogical thinking of a higher school teacher. Theoretical and practical (methodological) aspects of teachers' professional training: competence approach, p. 137-143 (Collective monograph, Yalta: RIO GPA, 2018) 
13. O.N. Rakitskaya, The problem of constructive professional thinking in the personal potential of a teacher, Potential of the individual: a complex problem, Intern. conference, 195-198 (Tambov, June 5, 2010)

14. E.N. Korneeva, Subject regulation of educational process, Psychology and pedagogics, 6, 48-53 (Herald of Kostroma state University, 2006)

15. T.G. Kiseleva, Socio-psychological features of level characteristics of professional pedagogical thinking in the assessment process. Psychology of professional pedagogical thinking, p. 89-116 (Monograph, Ed. by M.M. Kashapov, Moscow: Institute of psychology of the Russian Academy of Sciences, 2003)

16. L.S. Vygotsky, Collected works. In 5 parts. Part 1, 2, 3 (Moscow: Pedagog, 1983)

17. V.M. Vorobyov, N.L. Konovalova, Co-therapeutic computer system "Kelly". Methodological guidance, p. 168 (Saint Petersburg: Imaton, 2019)

18. V.F. Petrenko, Fundamentals of psychosemantics, p. 470 (Smolensk: The Publ. house SSU, 1997) 